\title{
EXPLORING THE CHANGES IN THE PSYCHIATRIC DIAGNOSIS SINCE THE INTRODUCTION OF FIFTH EDITION OF THE DIAGNOSTIC AND STATISTICAL MANUAL OF MENTAL DISORDERS
}

\author{
Manya Malhotra \\ College du Léman \\ DOI: 10.46609/IJSSER.2020.v05i01.011 URL: https://doi.org/10.46609/IJSSER.2020.v05i01.011
}

\begin{abstract}
The classification of diseases has been central to medical research because it determines standards of diagnosis and treatments. Research into the classification of mental disorders and the standards for their diagnosis is very recent. The most recent classifications by the American Psychiatric Association have been detailed in the Fifth Edition of The Diagnostic and Statistical Manual of Mental Disorders (DSM-5). This paper has sought to determine the impact of such classifications on the healthcare system and the lives of individuals and seeks to establish the efficacy of DSM-5. Even though the DSM-5 is rooted in empirical findings and is culturally sensitive, it's provisioning has also lead to higher rates of unnecessary medicalization. The paper has found that questions surrounding comorbidity of mental disorders are unanswered in DSM-5. Members of the Task Force responsible for drafting the Manual have had vested interests in pharmaceutical companies, which are expected to benefit from the most recent revisions of the DSM, especially due to the deletion of the "bereavement exclusion" for depressive disorders, which has led to the increase in subscription of antidepressants. This paper has found that transparency in research and accountability of those responsible for conducting it is imperative to ensure that such research abides by medical ethics and benefits the most vulnerable stakeholders in society.
\end{abstract}

Keywords: Psychiatric, Mental disorders, Medicalization, Diagnostic, DSM

\section{INTRODUCTION}

The Diagnostic and Statistical Manual of Mental Disorders (DSM) is a publication for the classification of mental disorders using a common language and standard criteria. The 


\section{International Journal of Social Science and Economic Research}

ISSN: $2455-8834$

Volume: 05, Issue: 01 "January 2020"

implications of this manual impact a plethora of stakeholders. It is not only used by clinicians and researchers, but also by corporations involved in the healthcare sector including, health insurance and pharmaceutical companies. Most importantly, however, it is used by instruments of the state machinery including psychiatric drug regulation agencies, the legal system, and policymakers. Mental health professionals use the manual to determine and help communicate a patient's diagnosis after an evaluation. Hospitals, clinics, and insurance companies often require a diagnosis supported by the DSM for all patients treated (Dalal \& Sivakumar, 2009). The DSM can be used clinically, or to categorize patients using established and amended diagnostic criteria. Changes in classifications of disorders in the DSM can also influence the profitability of corporations involved in the healthcare sector. Some studies done on specific disorders often recruit patients whose symptoms match the criteria listed in the DSM for that disorder (Dalal \& Sivakumar, 2009).

It is published, owned and trademarked by the American Psychiatric Association (APA). The DSM evolved from systems for collecting census and psychiatric hospital statistics, and from a United States Army manual. Revisions since its first publication in 1952 have incrementally added to the total number of mental disorders and removed those no longer considered to be mental disorders. The impact of these revisions is felt not only by those directly involved in the field of psychology and mental health but by society as a whole (Dalal \& Sivakumar, 2009). The American Psychiatric Association published the DSM-5 on 18th May 2013. It superseded DSMIV-TR, which was published in 2000. The development of this new edition began with a conference in 1999 and proceeded with the formation of a Task Force in 2007, which developed and field-tested a variety of new classifications (Wakefield, 2013).

In most respects, the DSM-5 is not greatly modified from the DSM-IV-TR; however, some significant differences exist between them. The most notable of these include the reconceptualization of Asperger syndrome from a distinct disorder to an autism spectrum disorder the elimination of subtypes of Schizophrenia; the deletion of the "bereavement exclusion" for depressive disorders; the renaming of gender identity disorder to gender dysphoria, along with a revised treatment plan for the same; the inclusion of binge eating disorder as a discrete eating disorder; and the splitting of disorders not otherwise specified into other specified disorders and unspecified disorders. Changes to the DSM were largely informed by advancements in neuroscience, clinical and public health needs, and identified problems with the classification system and criteria put forth in the DSM-IV. Much of the decision-making was also driven by a desire to ensure better alignment with the 11th version of the International Classification of Diseases (Regier, et. al., 2013). Various authorities including the British Psychological Association and the National Institute of Mental Health (United States) have criticized the fifth edition of the DSM both before and after it was formally published stemming 


\section{International Journal of Social Science and Economic Research}

ISSN: $2455-8834$

Volume: 05, Issue: 01 "January 2020"

primarily on the grounds of the lack of empirical support for DSM Revisions; and the presence of contradictions in the renewed manual. The psychiatric drug industry is also said to have unduly influenced the manual's content (Welch, et. al., 2013). The impact of changes in a manual as consequential as the DSM warrants an inquiry into the nature of revisions, the motives behind them and its impact.

\section{BACKGROUND}

The initial impetus for developing a classification of mental disorders in the United States was the need to collect statistical information. The American Psychiatric Association was formed as the Association of Medical Superintendents of American Institutions for the Insane in 1844 because the American Statistical Association reported errors in statements concerning nosology and the prevalence of insanity during the classification of data. In 1917, together with the National Commission on Mental Hygiene (now known as Mental Health America), the APA developed a new guide for mental hospitals called the Statistical Manual for the Use of Institutions for the Insane which included the twenty-two diagnoses (Deyoung, 2013). Even though these diagnoses would be revised several times by the APA over the years, the Statistical Manual for the Use of Institutions for the Insane was the first document to resemble the presentday DSM. Along with the New York Academy of Medicine, the APA also provided the psychiatric nomenclature subsection of the U.S. general medical guide (Deyoung, 2013). An APA Committee on Nomenclature and Statistics was empowered to develop a version of the Medical 203 - a classification scheme developed by the United States of America during the Second World War that classified 'mental disturbances experienced by soldiers in the war, for civilian use in the United States (Houts, 2000). This led to the release of the first Diagnostic and Statistical Manual of Disorders in 1952 (Houts, 2004). Since then the Manual has evolved and revised multiple times. It is considered to be a reflection of society and its amendments mark often reflect the progression of society. The APA listed homosexuality in the DSM as a sociopathic personality disturbance. Scientific Studies were was used to justify the inclusion of homosexuality as a disorder and it was attributed to a supposed pathological hidden fear of the opposite sex caused by traumatic parent-child relationships(Mayes, et. al., 200). This view was very influential in the medical profession. However, in the coming years, these claims were disproved by other studies (Mayes, et. al., 200). Not only has homosexuality not been considered a disorder since DSM-3 which was published in 1974, but it has also been accepted and normalized in numerous communities across the world since then. The DSM has been praised on grounds of being sensitive to sociological changes and grounding psychiatric diagnoses in empirical evidence. However, it has also been criticized on grounds of being prone to cultural bias, medicalizing human distress, being prone to corporate influence and drawing arbitrary lines between mental illness and normality (Frances, 2013). 
International Journal of Social Science and Economic Research

ISSN: $2455-8834$

Volume: 05, Issue: 01 "January 2020"

The 'ICD-10 Classification of Mental and Behavioural Disorders', published by the World Health Organization exists as an alternative to the Diagnostic and Statistical Manual. While the DSM is the most popular diagnostic system for mental disorders in the United States, the ICD is used more widely in Europe and other parts of the world, giving it a far larger reach than the DSM. Even Though recent editions of the DSM and ICD have become more similar due to collaborative agreements, each one contains information absent from the other (A.P.A., 2009). An international survey of psychiatrists in sixty-six countries that compared the use of the ICD10 and DSM-IV found the former was more often used for clinical diagnosis while the latter was more valued for research (Mezzich, 2002). Even though these the DSM and ICD are used in different parts of the world, they provide for codes that allow comparison and reference and also set up a system of checks and balances at the international level.

\section{DISCUSSION}

A DSM-5 Research Planning Conference was set up in 1999 jointly by the APA and the National Institute of Mental Health to define research priorities and shape the DSM-5. It was published in 2013 based on the work of a Task Force consisting of 27 members, set up by the APA in 2007 (First, 2002). The DSM-5 field trials were based on the test-retest repeatability which means that there was an agreement between the results of several successive tests. These tests involved different clinicians performing independent evaluations of the same patient- a common approach to the study of diagnostic reliability (Regier, et. al., 2007).

The Fifth Edition of the Diagnostic and Statistical Manual of Mental Disorders contains extensively revised diagnoses and has altered numerous psychological definitions. Intellectual developmental disorders were previously referred to as 'Mental Retardation'. Over time, the term started to be used as a slur and the APA decided to rename those disorders as 'Intellectual Disabilities' to maintain clarity in diagnosis and documentation. Asperger's Syndrome and Heller's Syndrome were reclassified as parts of Autism (A.P.A., 2013). The bereavement exclusion was removed as a diagnosis of major depression (Pies, 2014). Gender Identity disorder was removed from the list of sexual disorders, renamed into Gender Dysphoria and put in a separate category of its own. The name change was made due to the stigmatization of the term "disorder" and the growing use of "gender dysphoria" in literature, among specialists in the area, and in public discourse. Different diagnosis for Gender Dysphoria was created for children and adults to reflect the lower ability of children to have an insight into their experiences and the absence of the ability to express that insight (A.P.A., 2013). Gambling disorder and tobacco use disorder have been introduced to the category of substance-related and addictive disorders. Fresh research on obsessive-compulsive and related disorders led to the inclusion of four new disorders- excoriation (skin-picking) disorder, hoarding disorder, substance-/medication-induced 


\section{International Journal of Social Science and Economic Research}

ISSN: $2455-8834$

Volume: 05, Issue: 01 "January 2020"

obsessive-compulsive and related disorder, and obsessive-compulsive and related disorder due to another medical condition (A.P.A., 2013). Changes were also introduced in the classification and diagnosis of Bipolar Disorders, Anxiety Disorders, Dissociative Disorders and Trauma- and stressor-related disorders.

The DSM-5 has been criticized on the grounds of being unfairly influenced by the pharmaceutical industry. Critics claim that it compromises on medical ethics by seeking to promote the profit motives of pharmaceutical companies (Pies, 2014). About $68 \%$ of the DSM-5 task-force members and 56\% of the panel members reported having ties to the pharmaceutical industry. These ties which include shareholdings in pharmaceutical companies, serving as consultants to industry, or serving on company boards are considered by many to be conflicts of interest. (Harold, et. al., 2009). The APA mandated the DSM-5 task force members to sign a nondisclosure agreement, which effectively made the whole process the secretive. This erosion of transparency was criticized by Robert Spitzer and Alan Frances, heads of the DSM-3, and DSM-4 Task Forces respectively (Carey, 2008). The appointment of Kenneth Zucker and Ray Blanchard to the Task Force in May 2008 led to an internet petition to remove them. Zucker and Blanchard were accused of promoting hurtful theories during their careers (Chibbaro, 2008). They advocated the idea that children who are unambiguously male or female anatomically, but seem confused about their gender identity, can be treated by encouraging gender expression in line with their anatomy, hence characterizing transsexuality as not an essential aspect of the individual, but a misdirected sexual impulse (Osborne, 2008). The DSM-5 has also been criticized for being silent about the biological underpinnings of mental disorders and only accepting western psychology as the norm (Murphy, 2015). The British Psychological Society expressed concerns over the DSM-5 for basing diagnosis on social norms, leaving the definition of symptoms to subjective interpretations and being reflective of only present social expectations. Most importantly, it expressed concerns over the continued and continuous medicalization of natural and normal responses of individuals to their experiences (B.P.S., 2013). The classification of normal individual variations as illness benefits pharmaceutical companies at the cost of individuals. The removal of the bereavement exclusion in the diagnosis of major depression leads to the medicalization of ordinary grief and encourage over-prescription of antidepressants. However, academics claim that the risk of normalizing major depression disorder simply because it occurs in the context of recent bereavement justifies the removal of the bereavement exclusion in the diagnosis of major depression (Pies, 2014). The current systems of DSM-5 classification are also criticized because it actively encourages multiple diagnoses in the same person, which inflation of comorbidity rates. The unavailability of complex treatments required for comorbidity, especially in developing countries has made this classification impractical (Desai, 2006) 
International Journal of Social Science and Economic Research

ISSN: $2455-8834$

Volume: 05, Issue: 01 "January 2020"

\section{CONCLUSION}

The classification of psychiatric disorders as distinct entities is yet to be conclusive (Dalal \& Sivakumar, 2009). The principled critique of psychiatric disorder stems from the fact that attempts to demonstrate natural boundaries between related syndromes or a common syndrome and normality have thus far failed. Several disorders classified in the DSM/ICD have been found to cluster among the relatives of individuals with schizophrenia, major depression or bipolar affective disorder, and findings of such clusters have given rise to the concepts of "schizophrenia spectrum" and "affective spectrum" disorders, which makes classification flawed. Psychiatric comorbidity seems to be the rule rather than the exception (Kendell \& Jablenski, 2003). For example- the separation between depression and anxiety has been criticized because the most common form of affective disorder is mixed anxiety-depression, which is more common than each disorder alone. The DSM-5 is said to have made the treatment of disorders more complex, as the methodology leads to higher rates of diagnosis of comorbidity (Lecrubier, 2009).

In the face of criticism, the National Institute of Mental Health described the Diagnostic and Statistical Manual of Mental Disorders as a dictionary for Psychological Disorders and not a bible for classifying them. However, given the impact of the classifications extends from diagnosis and medication subscription to medical insurance and pharmaceutical sales. The changes in classification have been praised on the grounds of being culturally sensitive and rooted in empirical evidence. However, they have given rise to a plethora of problems for the most oppressed communities. The higher propensity of medicalization and diagnosis is bound to lead to an increase in sales of pharmaceutical drugs such as antidepressants. This is beneficial from the perspective of corporates, but not only does such medication have detrimental side effects on the health of patients, but they also put an unfair economic burden on them. The vested interest of the Task Force responsible for the classifications has been under question due to their stake in large scale pharmaceutical companies. Moreover, the procedure has also been tainted by the usage of non-disclosure agreements, that have eroded transparency. To improve further classifications and make them more conducive to the needs of vulnerable stakeholders in society, it is bound to ensure the accountability and independence of organizations responsible for publishing them.

Medical Research has far-reaching consequences on not only health but also public policy and economic productivity. Scientific research into psychiatric disorders is recent in comparison to research seeking solutions infections, pathogens or other diseases that impact the 'physical health' of individuals. The determination of foolproof characteristics requires an evolution of research which has not been achieved yet. However, it is imperative to ensure that the diagnosis 
International Journal of Social Science and Economic Research

ISSN: 2455-8834

Volume: 05, Issue: 01 "January 2020"

of individuals is done in their best interests and to ensure that the basis of such diagnosis is rooted only in scientific research and discovery, and not vested interests of individuals.

\section{BIBLIOGRAPHY}

American Psychiatric Association (2013). Highlights of Changes from DSM-IV-TR to DSM-5. Accessed on 7th December 2019

American Psychiatric Association (2009). ICD VS. DSM. Monitor on Psychology. Accessed on 7th December 2019

British Psychological Society. (2011). Response to the American Psychiatric Association: DSM5 Development. Accessed on 4th December 2019

Carey, B. (2008). Psychiatrists Revise the Book of Human Troubles. The New York Times. Accessed on 7th December 2019

Chibbaro, L. (2008). Activists alarmed over APA: Head of psychiatry panel favors 'change' therapy for some trans teens". Washington Blade, Accessed on 4th December 2019

Dalal, P.K., Sivakumar, T. (2009). Moving towards ICD-11 and DSM-V: Concept and evolution of psychiatric classification. Indian Journal of Psychiatry, Accessed on 6th December 2019

Desai, N.G. (2006). Comorbidity in psychiatry: Way forward or a conundrum? Indian Journal of Psychiatry, Accessed on 7th December 2019

Deyoung, N. (2013). History of the DSM. Purdue University. Accessed on 5th December 2019

Frances, A. (2013). The New Crisis in Confidence in Psychiatric Diagnosis. Annals of Internal Medicine, Accessed on 5th December 2019

First, M.B. (2002). A Research Agenda for DSM-V: Summary of the DSM-V Preplanning White Papers Published in May 2002. DSM-V Prelude Project, American Psychiatric Association, Accessed on 7th December 2019

Harold, J.,Cosgrove, L., Krimsky, S. (2009). Developing Unbiased Diagnostic and Treatment Guidelines in Psychiatry. New England Journal of Medicine, Accessed on 7th December 2019 
International Journal of Social Science and Economic Research

ISSN: 2455-8834

Volume: 05, Issue: 01 "January 2020"

Houts, A.C. (2000). Fifty years of psychiatric nomenclature: Reflections on the 1943 War Department Technical Bulletin, Medical 203. Journal of Clinical Psychology, Accessed on 6th December 2019

Kendell, R.E., Jablensky, A. (2003) Distinguishing between the validity and utility of psychiatric diagnosis. American Journal of Psychiatry. Accessed on 4th December 2019

Lecrubier, Y. (2008). Refinement of diagnosis and disease classification in psychiatry. European Archives of Psychiatry and Clinical Neuroscience, Accessed on 7th December 2019

Mayes, R., Bagwell, C., Jennifer, L. (2009). The Transformation of Mental Disorders in the 1980s: The DSM-III, Managed Care, and "Cosmetic Psychopharmacology.Medicating Children: ADHD and Pediatric Mental Health. Harvard University Press, Accessed on 6th December 2019

Mezzich, J.E. (2002). International Surveys on the Use of ICD-10 and Related Diagnostic Systems. Psychopathology, Accessed on 7th December 2019

Murphy, D. (2015). Deviant deviance": Cultural diversity in DSM-5. Accessed on 4th December 2019

Osborne, D. (2008). Flap Flares Over Gender Diagnosis. Gay City News, Accessed on 4th December 2019

Pies, R. (2013). The Bereavement Exclusion and DSM-5: An Update and Commentary. Innovations in Clinical Neuroscience, Accessed on 7th December 2019

Regier, D.A., Kuhl, E.A., Pies, R. (2013).The DSM-5: Classification and criteria changes. World Psychiatry, Accessed on 5th December 2019

Wakefield, J.C. (2013). DSM-5: An Overview of Changes and Controversies. Clinical Social Work Journal, Accessed on 6th December 2013

Welch, S., Klassen, C., Borisova, O., Clothier, H. (2013). The DSM-5 controversies: How should psychologists respond?. Canadian Psychology, Accessed on 5th December 2019 